\title{
DIAGNÓSTICO DA GESTÃO COSTEIRA E DAS POLÍTICAS PÚBLICAS DO MUNICÍPIO DE SÃo Francisco do SUL, SC, BRASIL
}

\author{
André de Souza de Lima"; \\ Apoena Calixto Figueirôa2; \\ Victor Gabriel Zapelini Guião Coelho'; \\ Celso Voos Vieira3; \\ Francisco Arenhart da Veiga Lima ${ }^{1}$; \\ Marinez Eymael Garcia Scherer ${ }^{1}$; \\ ${ }^{1}$ UFSC- Universidade Federal de Santa Catarina \\ 2 ICMBio - Instituto Chico Mendes de Conservação da Biodiversidade \\ ${ }^{3}$ Universidade da Região de Joinville
}

\section{Resumo}

Foram analisadas as ações relacionadas ao gerenciamento costeiro no município de São Francisco do Sul/SC para obter um panorama geral com relação à integração entre as secretarias municipais. Para isso, foi realizada a aplicação de um Decálogo, que consiste em dez temas chave que possibilitam a análise da estrutura pública municipal em relação ao gerenciamento costeiro. Para a análise foram realizadas reuniões com a prefeitura e consultas a documentos públicos e materiais cartográficos. Constatou-se que a prefeitura apresenta diversas iniciativas no setor ambiental, todavia é incipiente em relação ao gerenciamento costeiro integrado. Este conhecimento poderia dar as primeiras diretrizes para que seja possível o aperfeiçoamento dos atuais processos de gestão ambiental e a elaboração de uma Política de Gerenciamento Costeiro.

Palavras-chave: Gerenciamento Costeiro; Políticas ambientais; Decálogo costeiro.

\begin{abstract}
Were analyzed actions related to the current coastal management in São Francisco do Sul/SC. The work was centered to obtain a general picture regarding the interactions between policy scales and management levels. Decalogue application was used to analyze the existing municipal public structure in relation to coastal management. A series of meetings was held in São Francisco do Sul with public consultations addressing documents and cartographic materials. It was revealed that São Francisco do Sul has had several initiatives in the environmental sector, however, it is still being under development in relation to integrated coastal management. This knowledge could provide a direction to improve the current processes of coastal management and the creation of public policies.
\end{abstract}

Key words: Coastal Management, Environmental Policies, Coastal Decalogue. 
A s políticas relacionadas ao gerenciamento costeiro no Brasil tiveram origem no final da década de 1980, sete anos após a publicação da Política Nacional do Meio Ambiente - PNMA (BRASIL, 1981). O Plano Nacional de Gerenciamento Costeiro - PNGC (BRASIL, 1988), fez parte da Política Nacional para os Recursos do Mar - PNRM (BRASIL, 2005) e Política Nacional do Meio Ambiente - PNMA.

Na segunda metade da década de 1990, através da Resolução da Comissão Interministerial para os Recursos do Mar (CIRM 5/1997), instituiu-se o Plano Nacional de Gerenciamento Costeiro II - PNGC II, o qual dá subsídios a política para a gestão da zona costeira.

Segundo Diederichsen et al (2013), o arcabouço existente para o Gerenciamento Costeiro do Brasil foi apresentado no PNGC e no Decreto Federal no 5.300/2004, que o regulamenta e estabelece critérios de gestão da orla marítima, assim como cria novos instrumentos de gestão. Já para o Estado de Santa Catarina, em 2005 foi publicado o Plano Estadual de Gerenciamento Costeiro (PEGC), regulamentado pelo Decreto $n^{\circ}$ 5.010/2006. O município de São Francisco do Sul, por sua vez, integra o Setor 1 do Plano de Gestão da Zona Costeira de Santa Catarina, um dos instrumentos do Plano Estadual.

Conforme o PNGC II entende-se por Zona Costeira o espaço geográfico de interação do ar, do mar e da terra (BRASIL, 1988), sendo esta, dividida em duas faixas: a) Faixa Marítima - é a faixa que se estende mar afora distando 12 milhas marítimas, compreendendo a totalidade do Mar Territorial; b) Faixa Terrestre - é a faixa do continente formada pelos municípios que sofrem influência direta dos fenômenos ocorrentes na Zona Costeira (FREIRE, 2002). De acordo com esta definição e dados do IBGE (2010b), o território do município de São Francisco do Sul encontra-se totalmente inserido na Zona Costeira brasileira.

Para contribuir com o planejamento e gestão da zona costeira, juntamente do PNGC II foram instituídos sete instrumentos do gerenciamento costeiro (BRASIL, 2004, ASMUS et al., 2006), dos quais se destacam o Plano de Gestão da Zona Costeira, o Projeto de Gestão Integrada da Orla Marítima, o Plano Estadual de Gerenciamento Costeiro e o Plano Municipal de Gerenciamento Costeiro e o Zoneamento ecológico-econômico da Zona Costeira.

\section{Área de estudo}

O município de São Francisco do Sul (Figura 1) possui $498 \mathrm{~km}^{2}$ de área territorial, localiza-se na região nordeste do estado de Santa Catarina e é banhado pelas águas do Oceano Atlântico, na vertente leste do município e pelas águas do sistema estuarino Baía da Babitonga, no setor oeste. 


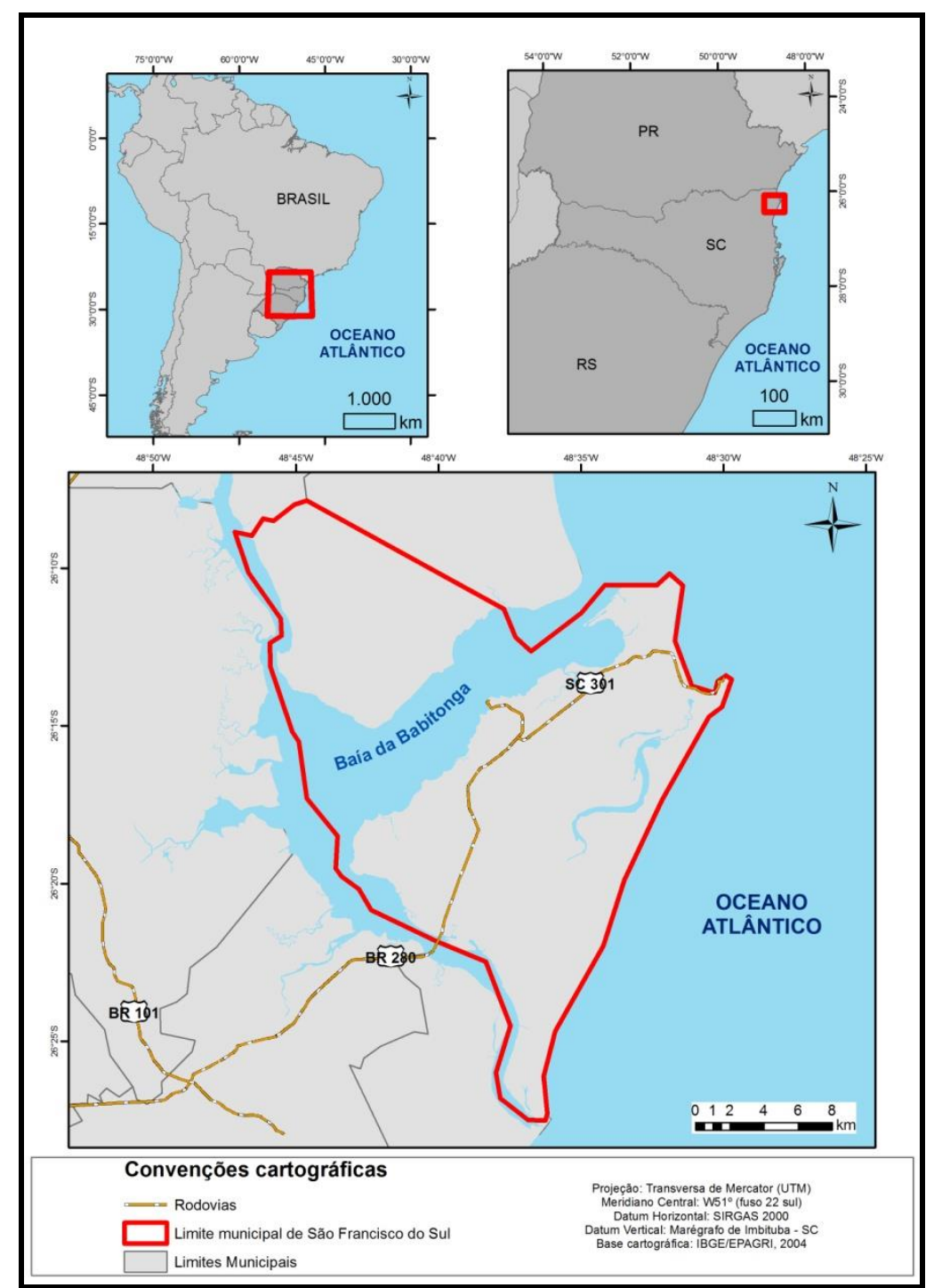

Figura 1. Localização do município de São Francisco do Sul, Santa Catarina. Fonte: elaboração própria.

São Francisco do Sul é a terceira cidade mais antiga do Brasil, descoberta em 1504, entretanto o início da colonização aconteceu apenas em 1658 e somente no final do século XIX foi reconhecida como cidade. O crescimento econômico do município historicamente está associado a atividade portuária nas águas protegidas da baía de Babitonga, à construção da rede ferroviária, seguida décadas mais tarde pela construção do porto público, o qual figura como $7^{\circ}$ maior do país em movimentação de cargas, responsável por grande parte da movimentação econômica de toda região (ANTAQ, 2018; LIMA \& SCHERER, 2017). A vocação portuária do município, influenciada pelas condições geográficas da baía de Babitonga, como área abrigada à ventos e ondulações, deve-se fortalecer com a consumação de demais instalações portuárias projetadas para as margens da baía.

Do ponto de vista ambiental, a diversidade de ecossistemas do município se estende desde a baía da Babitonga, que abriga a última grande ocorrência de manguezais no hemisfério sul (CREMER et al, 2006) assim como mais de cinquenta ilhas costeiras, praias arenosas, dunas e 
grandes áreas de restinga (SANTA CATARINA, 2010). Segundo o Instituto Brasileiro de Geografia e Estatística (2010), foram recenseadas 42.520 pessoas residentes no município, totalizando uma densidade demográfica em $86,25 \mathrm{hab} / \mathrm{km}^{2}$. No entanto, durante a temporada de verão, o aumento da população no setor Norte da Ilha, sobretudo próximo aos balneários, oferece forte pressão aos ecossistemas costeiros.

Desde a origem do município a ocupação foi realizada na região litorânea, por conta das facilidades de subsistência e obtenção de renda da população, bem como pela localização geográfica. Até hoje, mais da metade da população habita a região costeira do município (LIMA \& SCHERER, 2017).

Considerando todos os aspectos mencionados, gerir de maneira integrada um município da zona costeira se torna um grande desafio. A pesquisa teve como principal objetivo diagnosticar a gestão costeiro no município de São Francisco do Sul em relação às políticas existentes, e como o mesmo se desenvolve junto à prefeitura, a fim de conhecer as medidas já tomadas, bem como as deficiências e dificuldades encontradas pela gestão pública para a gestão costeira integrada municipal.

\section{Materiais e métodos}

O método utilizado consiste em avaliar o gerenciamento costeiro de São Francisco do Sul/SC com base em dez indicadores pré-estabelecidos pelo Decálogo da gestão costeira, desenvolvido e proposto por Barragán Muñoz (2004), a fim de diagnosticar a atual situação do poder público local em relação à zona costeira.

O decálogo (BARRAGÁN MUÑOZ, 2004) sugere a existência de dez princípios básicos no processo e estratégias de gestão integrada da zona costeira que devem estar presentes nas estratégias de gestão e políticas públicas, a fim de possibilitar a governança costeira (Tabela 1). É importante salientar que o Decálogo tem sido utilizado constantemente como base para a produção de diagnósticos em estudos relacionados à gestão costeira, bem como em outras áreas do conhecimento. Essa metodologia já foi aplicada por diversos autores em 13 países (BARRAGÁN, 2010; 2011; 2012), assim como em nível regional (BARRAGÁN et al., 2008; ONETTI et al, 2011; ANDRADE \& SCHERER, 2014), e municipal (DIEDERICHSEN et al., 2013). 
Tabela 1. Indicadores e objetivos propostos no Decálogo da gestão

\begin{tabular}{|c|c|c|}
\hline & Indicadores & Objetivos \\
\hline 1) & Política Pública para o litoral & $\begin{array}{l}\text { Conhecer se existe uma política institucional sobre a gestão costeira integrada } \\
\text { (GCI), que seja explícita e de conhecimento público. }\end{array}$ \\
\hline 2) & Estrutura Normativa & $\begin{array}{l}\text { Precisar a base normativa que regulamenta a GCI, a gestão de recursos ou as } \\
\text { atividades costeiras. }\end{array}$ \\
\hline 3) & Competências & $\begin{array}{l}\text { Decifrar o esquema de distribuição de responsabilidades públicas em relação à } \\
\text { gestão de espaços e recursos costeiros. }\end{array}$ \\
\hline 4) & Instituições públicas & $\begin{array}{l}\text { Precisar as instituições públicas mais envolvidas nos assuntos de gestão costeira e } \\
\text { marinha. }\end{array}$ \\
\hline 5) & Instrumentos e Estratégias & Determinar os instrumentos estratégicos e operativos que interessam à GCI. \\
\hline 6) & Formação e Capacitação & $\begin{array}{l}\text { Determinar o sistema de capacitação de gestores e administradores públicos vincu- } \\
\text { lados a questões de GCI. }\end{array}$ \\
\hline 7) & Recursos Econômicos & Conhecer as bases econômico-financeiras sobre as quais se sustenta a GCI. \\
\hline 8) & Informação e Conhecimento & $\begin{array}{l}\text { Determinar o nível de conhecimento existente sobre a zona costeira (físico e natu- } \\
\text { ral, social e econômico, jurídico e administrativo), assim como a acessibilidade } \\
\text { desta informação. }\end{array}$ \\
\hline 9) & Educação para cidadania & $\begin{array}{l}\text { Identificar quais são as principais iniciativas de educação relacionadas com a } \\
\text { sustentabilidade costeira e marinha, disponíveis para os usuários da zona costeira. }\end{array}$ \\
\hline
\end{tabular}

10) Participação Relacionar a tomada de decisões com a participação cidadã.

Fonte: Adaptado de Barragán (2004).

No Brasil, além do diagnóstico realizado pela Rede Ibero Americana de Manejo Costeiro Integrado (Rede Ibermar), diversos estudos têm sido realizados a partir da utilização do Decálogo da gestão costeira. No contexto brasileiro, tem-se o caso da implementação do gerenciamento costeiro municipal de Anchieta (SCHERER et al., 2013), no litoral centro sul do Espírito Santo; do diagnóstico da gestão costeira do município de Florianópolis (DIEDERICHSEN et al., 2013) e da análise da implementação do Projeto Orla em Bombinhas (GUIÃO, 2015), região centro, e centro norte de Santa Catarina, respectivamente.

Para acessar as informações necessárias para a elaboração da análise baseada no Decálogo, utilizou-se como fonte de dados: documentos públicos, informativos e materiais cartográficos disponibilizados pela prefeitura de São Francisco do Sul, bem como artigos acadêmicos, trabalhos científicos e informações contidas em sítios virtuais. O contato com a prefeitura foi estabelecido a partir de comunicação telefônica, correio eletrônico e de maneira presencial, por meio de entrevista semi-estruturada (LAVILLE e DIONE, 1999), pautada nas etapas do decálogo, tendo a secretaria de meio ambiente municipal, como principal interlocutora.

\section{Resultados e discussão}

O município de São Francisco do Sul não possui nenhuma política instituída exclusiva para conservação e gestão costeira. Não existem também decretos e/ou normas referentes ao mesmo objeto. A Tabela 4 apresenta um resumo geral em relação aos itens analisados na pesquisa. 


\section{Política}

Atualmente o município não possui um Plano Municipal de Gerenciamento Costeiro, sendo assim o Plano Nacional de Gerenciamento Costeiro (PNGC II) e o Plano Estadual de Gerenciamento Costeiro (PEGC) são responsáveis por aportar as diretrizes para o gerenciamento costeiro de São Francisco do Sul.

A prefeitura do município deixa claro que o gerenciamento da orla marítima é prioridade para a atual gestão. No entanto, Lima et al (2017), apontam que cerca de $70 \%$ da faixa marítima do município encontra-se preservada, desse modo deveria ser prioridade para a gestão municipal, o ordenamento territorial como um todo, sendo que as áreas críticas localizam-se em todo município, não apenas em sua orla.

Encontra-se em andamento a tentativa de criação de uma política pública em conjunto com a Associação de municípios do nordeste de Santa Catarina (AMUNESC) para criação de diretrizes de planejamento territorial para São Francisco do Sul. Até o momento foi publicado o Decreto $\mathrm{n}^{\circ}$ 2.664, de 8 de agosto de 2017, que se refere ao processo de revisão do Plano Diretor Participativo de São Francisco do Sul.

\section{Normativa}

O município de São Francisco do Sul não possui legislação específica para gestão costeira e atualmente, as únicas leis que dispõe sobre o tema são de âmbito federal e estadual (Tabela 2). Para o planejamento de seu território, o município possui um Plano Diretor publicado em 2006 (Lei Complementar n०17 de dezembro de 2006). No entanto, a Associação dos Municípios de Nordeste de Santa Catarina (AMUNESC) iniciou em 2017 a assessoria para revisão do atual Plano Diretor.

Não obstante, a Lei de uso e ocupação do solo 763/1981, que dispõe sobre o zoneamento do município, é utilizada como base para o planejamento urbano, em conjunto com as leis complementares no 43/2013 e n 44/2013.

O Código Municipal de Meio Ambiente encontra-se em fase de elaboração junto ao ConseIho Municipal de Meio Ambiente. Mesmo sem o texto aprovado, alguns artigos estão sendo elaborados desde 2016, em conjunto com o corpo técnico da prefeitura, na Comissão Municipal de Meio Ambiente.

Em relação à legislação federal para a zona costeira, sobretudo para gestão de praias, a Lei $n^{0}$ 13.240/2015, propõe estabelecer convênio com a Secretaria do Patrimônio da União (SPU), com o objetivo de transferir a gestão dessas áreas para o município. Depois da adesão ao convênio, o município tem três anos para iniciar a elaboração do Projeto Orla, que constitui no ordenamento dos espaços litorâneos sob domínio da União, aproximando as políticas ambiental e patrimonial, voltadas ao uso sustentável (Brasil, 2004). 
Tabela 2. Principais normas vigentes utilizadas pela prefeitura de São Francisco do Sul

\begin{tabular}{|c|c|c|}
\hline Legislação Federal & Legislação Estadual & Legislação Municipal \\
\hline Lei $\mathrm{n}^{\circ} 12.651 / 2012$ - Código Florestal & $\begin{array}{l}\text { Lei } n^{\circ} 14.675 / 2009 \\
\text { Código Estadual de Meio Ambiente }\end{array}$ & $\begin{array}{l}\text { Lei Complementar 17/2006 (Plano } \\
\text { Diretor) }\end{array}$ \\
\hline $\begin{array}{l}\text { Lei } n^{\circ} 11.428 / 2006 \\
\text { - Lei da Mata Atlântica }\end{array}$ & $\begin{array}{l}\text { Decreto } \mathrm{n}^{\circ} 5.010 / 2006 \\
\text { Plano Estadual de Gerenciamento Cos- } \\
\text { teiro }\end{array}$ & $\begin{array}{l}\text { Lei } n^{\circ} 763 / 1981 \text { Lei de Uso e Ocupação } \\
\text { do Solo }\end{array}$ \\
\hline $\begin{array}{l}\text { Lei } \mathrm{n}^{\circ} 7.661 / 1988 \text { - Plano Nacional de } \\
\text { Gerenciamento Costeiro }\end{array}$ & 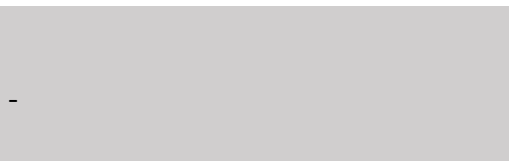 & $\begin{array}{l}\text { Lei Complementar n }{ }^{\circ} 43 / 2013 \text { e } \\
n^{\circ} 44 / 2013 \text { que dispõem sobre o zonea- } \\
\text { mento do município de São Francisco } \\
\text { do Sul }\end{array}$ \\
\hline $\begin{array}{l}\text { Lei } n^{\circ} \text { 9.636/1998 - Patrimônio da Uni- } \\
\text { ão e terras da Marinha }\end{array}$ & - & $\begin{array}{l}\text { Código Municipal de Meio Ambiente } \\
\text { (em fase de aprovação na câmara muni- } \\
\text { cipal desde 2015) }\end{array}$ \\
\hline $\begin{array}{l}\text { Decreto-Lei no 9.760/1946 - Patrimônio } \\
\text { da União e terras da Marinha }\end{array}$ & - & $\begin{array}{l}\text { Lei municipal n }{ }^{\circ} 603 / 1976 \text {, que dispõe } \\
\text { sobre o código de obras de São Francis- } \\
\text { co do Sul }\end{array}$ \\
\hline
\end{tabular}

Fonte: Elaboração própria.

\section{Competências}

Devido à falta de legislação e políticas públicas relacionadas ao gerenciamento costeiro no município de São Francisco do Sul, não é possível definir o que compete a cada órgão ou setor no município. Os conceitos relacionados ao gerenciamento costeiro são pouco conhecidos pelos funcionários e gestores e durante os diálogos estabelecidos entre o pesquisador e os correspondentes do município. Muitas vezes o projeto orla foi mencionado como sinônimo de gerenciamento costeiro.

A Lei municipal n 603/1976 que instituiu o código de obras de São Francisco do Sul, além de vetar construções na orla terrestre, sobretudo em terrenos de marinha, definiu a competência para fiscalização dessa restrição de ocupação, a qual não foi aplicada, fazendo com que os loteamentos criados em terrenos de marinha, sejam até hoje uma lacuna na regularização fundiária no município.

A secretaria de meio ambiente é a mais engajada no assunto, sendo que, mesmo declarando que os maiores problemas do município não se encontram somente na faixa de orla marítima, existe o interesse em aplicar o Projeto Orla no município.

\section{$\underline{\text { Instituições }}$}

São Francisco do Sul possui nove secretarias municipais que contribuem para o seu desenvolvimento (Tabela 3). Destas, quatro estão diretamente envolvidas com o planejamento territorial e urbano (Meio Ambiente, Obras, Infraestrutura, Urbanismo e Integração - SEINFRA e Desenvolvimento Econômico Sustentável).

A Secretaria de Infraestrutura, Urbanismo e Integração é responsável pelo planejamento urbano e pela publicação do Plano Diretor, bem como da criação de normas e posturas para a utilização do território, como o código de edificações. A secretaria é responsável pelo cadastro técnico municipal que visa, através de informações georreferenciadas, elaborar um planejamento 
multisetorial na prefeitura. A secretaria é composta por um corpo multidisciplinar que possui a missão de planejar desde a economia do município até o seu território.

A Secretaria de Desenvolvimento Econômico Sustentável, além de atuar diretamente com o porto - que representa um dos grandes responsáveis pela soma do PIB municipal, desenvolve a economia através do turismo e de ações de incentivo ao comércio local.

Já a Secretaria de Meio Ambiente, é responsável por auxiliar na administração pública municipal através da fiscalização e regulação da ocupação do território com base no zoneamento da cidade. A secretaria também busca conscientizar os munícipes com programas de educação ambiental e promove, também, a recuperação de áreas degradadas.

Tabela 3. Estrutura de governo do município

\begin{tabular}{|c|c|c|c|c|}
\hline GOVERNO & SECRETARIAS & GERÊNCIAS & CONSELHOS & DIRETORIAS \\
\hline Prefeito & Atendimento ao cidadẫo & Agricultura & $\begin{array}{l}\text { Assistência Social - CMAS } \\
\text { Câmara Intersetorial Municipal de }\end{array}$ & Demtran \\
\hline Vice-prefeito & $\begin{array}{l}\text { Desenvolvimento } \\
\text { Econômico Sustentável } \\
\text { Desenvolvimento Social }\end{array}$ & Comunicaçẫo Social & $\begin{array}{l}\text { Segurança Alimentar e Nutricional } \\
\text { (CAISAN) }\end{array}$ & $\begin{array}{l}\text { Fundação Cultural } \\
\text { Ilha }\end{array}$ \\
\hline \multirow{9}{*}{$\begin{array}{l}\text { Gabinete do Prefeito } \\
\text { Gabinete do Vice- } \\
\text { prefeito } \\
\text { NAG - Núcleo Avançado } \\
\text { de Gestẫo }\end{array}$} & e da Cidadania & Esportes & Conselho Municipal de Educaçẫo & \\
\hline & & Habitação e Assuntos & Conselho Municipal dos Direitos da & \\
\hline & Educação e Cultura & Fundiarios & Pessoa com Deficiência - COMDE & \\
\hline & $\begin{array}{l}\text { Finanças, Administração } \\
\text { e Gestão de Pessoa } \\
\text { Infraestrutura. }\end{array}$ & $\begin{array}{l}\text { Intendência do Distrito } \\
\text { do Saí }\end{array}$ & $\begin{array}{l}\text { Direito da Criança e do } \\
\text { Adolescente - CMDCA }\end{array}$ & \\
\hline & Urbanismo e Integraçẫo & $\begin{array}{l}\text { Intendência do Ervino } \\
\text { Intendência dos }\end{array}$ & Direitos da Mulher - CMDM & \\
\hline & Meio Ambiente & Balneários & Direitos do Idoso - CMDI & \\
\hline & Obras Saúde & Pesca & & \\
\hline & & Porto & & \\
\hline & & Turismo e Lazer & & \\
\hline
\end{tabular}

Fonte: Prefeitura Municipal de São Francisco do Sul (2017).

Apenas três ONGs foram mencionadas pela prefeitura por participar diretamente dos debates envolvendo gerenciamento costeiro, entretanto as mesmas não participam da tomada de decisões, apesar da habitual presença junto aos órgãos gestores do município: Instituto Restinga, Instituto Conservar, Associação Movimento Ecológico Carijós (AMECA).

\section{Instrumentos}

Devido à inexistência de uma política municipal, os instrumentos existentes para o gerenciamento costeiro no município de São Francisco do Sul são os instrumentos criados pelo PNGC. Cabe ressaltar que, no momento da elaboração da pesquisa, nenhum instrumento se encontra em desenvolvimento no município.

Com relação ao Projeto Orla, um dos instrumentos do PNGC II, a prefeitura de São Francisco do Sul assinou em janeiro de 2013 o termo de adesão associado ao processo $n^{\circ}$ 04972.000800/2012-36. No entanto, o projeto não foi elaborado até o momento, assim como não foram realizadas quaisquer ações relacionadas ao mesmo. 


\section{Formação e sustentabilidade}

No quesito formação e sustentabilidade, o município possui apenas uma Universidade, a qual tem três campi, sendo que sua sede fica em Joinville. A Universidade da Região de Joinville (UNIVILLE - campus São Francisco do Sul) oferece apenas três cursos: Administração, Ciências Biológicas e Biologia Marinha. Entretanto, o curso de Geografia (atualmente suspenso) e Engenharia Ambiental do campus Joinville apresentam constantes pesquisas tendo como objeto de estudo o município de São Francisco do Sul e o complexo estuarino da baía da Babitonga, devido a sua diversidade ambiental.

Além disso, em relação a instituições de ensino, destaca-se o Instituto Federal Catarinense - IFC, bem como as instituições de ensino superior à distância FAEL, UniCesumar e Uninter. A prefeitura de São Francisco do Sul, em parceria com a AMUNESC entre 2012 e 2016, disponibilizaram uma série de capacitações para os colaboradores das diversas secretarias municipais. Em quatro anos, consolidaram-se sete capacitações, com destaque para o tema "Gerenciamento Costeiro", ministrado pela Secretaria Estadual de Desenvolvimento Sustentável e pela Secretaria de Desenvolvimento Regional.

Além disso, a Prefeitura disponibiliza uma série de capacitações gratuitas, principalmente para cooperativas de reciclagem e capacitação em escolas públicas. Os projetos "Conhecendo nosso território" "Programa mãos na terra" e "Permacultura na escola" são destaques entre os 28 programas de educação ambiental em ação em 2017. Os projetos ainda têm como objetivo capacitar os professores da rede pública municipal para que os programas possam ser integrados na rede de ensino independente da gestão vigente do poder executivo.

\section{Recursos}

Não existem recursos ou fundos exclusivos para o gerenciamento costeiro no município. A não existência de uma política pública direcionada ao tema dificulta a alocação de verba. O plano plurianual também não disponibiliza fundos.

Conforme informações recebidas durante reunião na secretaria de meio ambiente, nenhum recurso federal e/ou estadual é recebido com relação ao gerenciamento costeiro no município. Também já houve a tentativa de alocação de verba por meio de parcerias com empresas privadas, resumindo-se a patrocínios para programas de educação ambiental, porém nenhum recurso específico a gestão costeira.

Atualmente a Ação Civil Pública n 2008.72.01.0006302, prevê recursos para reverter danos ambientais de um acidente com embarcação marítima. Os recursos serão destinados a criação de uma Unidade de Conservação no setor continental do município, com o objetivo de proteger os principais recursos hídricos do município e, além disso, melhorar o setor de fiscalização. A Secretaria Municipal de Meio ambiente, tem como objetivo até 2020 criar um fundo próprio para manejo da orla, no qual $20 \%$ do fundo municipal de meio ambiente seja destinado para o desenvolvimento do Projeto Orla. 


\section{Conhecimento e informação}

Durante o ano de 2013, o projeto intitulado "Projeto Orla em São Francisco do Sul - Subsídios para a implantação", o qual foi financiado pelo Fundo de Apoio a Pesquisa - FAP da UNIVILLE, elaborou todo o diagnóstico com base nos volumes publicados dando condição à prefeitura de conhecer a atual situação de sua orla marítima (LIMA, VIEIRA, SCHERER, 2017). No entanto, todo o material gerado pelo projeto atualmente é utilizado apenas para fiscalização e licenciamento ambiental da orla marítima.

A prefeitura de São Francisco do Sul lançou o primeiro volume do Jornal Meio Ambiente em Foco, publicado no primeiro semestre de 2017, o qual apresenta seus projetos envolvendo desenvolvimento econômico e sustentabilidade, projetos de educação ambiental, a operação estrada limpa, projeto de recuperação das áreas de restinga degradadas nas praias de Ubatuba e Itaguaçu, Licenciamento Ambiental, e o principal programa de educação ambiental intitulado "Programa conhecendo nosso território".

\section{Educação e sustentabilidade}

A secretaria de meio ambiente é responsável por 28 projetos de educação e conscientização ambiental e urbanística junto a escolas e a comunidade de São Francisco do Sul.

Outra iniciativa é a distribuição de placas em todo o município, mencionando cuidados com a fauna local, revitalização de mata nativa no centro histórico e educação infantil. Tais placas identificam áreas de marinha, restrições urbanísticas de uso referentes ao zoneamento e tipos de Área de Preservação Permanente (APP), bem como indicam a necessidade de consulta à prefeitura antes do estabelecimento de construções. Mesmo sendo uma ação pequena - de cerca de 100 placas, a prefeitura julga o resultado satisfatório e mais eficiente do que uma série de outras medidas já tomadas anteriormente.

O Projeto Babitonga Ativa (2017) constitui outra importante iniciativa no contexto da promoção à educação e sustentabilidade costeira da região da baía da Babitonga. Idealizada pela universidade Univille, de Joinville, é integrada por demais setores governamentais, econômicos e socioambientais da região. O projeto integra os 6 municípios banhados pelas águas da baía, incluindo São Francisco do Sul, e vem desenvolvendo nos últimos anos, documentos contendo diagnósticos socioambientais e estratégias de governança ambiental da região, incluindo as oportunidades da construção de uma rede de monitoramento integrado e o Planejamento Espacial Marinho (PEM) para a região.

\section{Participação}

Poucas foram as ações de incentivo a participação cidadã junto ao órgão público municipal. Nos últimos anos, o Plano Diretor careceu de audiências públicas junto à comunidade de São Francisco do Sul. Outra ação que será promovida, em que a participação da população será necessária, é a atual elaboração e aprovação do Código Municipal de Meio Ambiente, a qual ainda se encontra em andamento e aprovação junto ao Conselho Municipal de Meio Ambiente. 
Demais oportunidades de participação social na discussão da cidade estão centradas na realização de audiências públicas, a exemplo das ocorridas no ano de 2017 , sobre a potencial instalação de um grande projeto portuário no município, denominado Porto Brasil Sul. Considerando a existência de ao menos mais 03 terminais portuários projetados para as margens franciscanas da baia de Babitonga - estaleiro CMO, Terminal Graneleiro Babitonga e Terminal portuário Mar Azul - é de se esperar a realização de uma sequência de audiências públicas para o futuro próximo.

A população é convocada para audiências públicas e comparece em pequeno número, enquanto as associações de moradores têm sua participação diretamente associada a interesses locais e próprios. A prefeitura, sobretudo a secretaria de meio ambiente, tem a pretensão de aplicar o projeto orla no município dentro dos próximos anos, o que implicará na necessidade de participação cidadã nas tomadas de decisão que envolvem a orla marítima do município.

Tabela 4. Diagnóstico do Decálogo

\begin{tabular}{|c|c|c|}
\hline & Item do Decálogo & Diagnóstico \\
\hline & Política & Atualmente não existe nenhum plano municipal de gerenciamento costeiro. \\
\hline 2) & Normativa & $\begin{array}{l}\text { O ordenamento territorial é regido pela Lei de uso e ocupação do solo 763/1981 e Leis Comple- } \\
\text { mentares } n^{\circ} 43 / 2013 \text { e nº4/2013 }\end{array}$ \\
\hline 3) & Competências & $\begin{array}{l}\text { Devido à falta de legislação e políticas públicas relacionadas ao gerenciamento costeiro no muni- } \\
\text { cípio de São Francisco do Sul, não é possível definir o que compete a cada órgão ou setor no muni- } \\
\text { cípio. }\end{array}$ \\
\hline 4) & Instituições & $\begin{array}{l}\text { Três órgãos de governo estão diretamente ligadas ao gerenciamento costeiro em São Francisco do } \\
\text { Sul: Secretaria de Infraestrutura, Urbanismo e Integração; Secretaria de Desenvolvimento Econô- } \\
\text { mico Sustentável; Secretaria de Meio Ambiente. }\end{array}$ \\
\hline 5) & Instrumentos & $\begin{array}{l}\text { Devido a inexistência de uma política municipal, os únicos instrumentos existentes para o gerenci- } \\
\text { amento costeiro no município de São Francisco do Sul são os instrumentos criados pelo Plano } \\
\text { Nacional de Gerenciamento Costeiro. }\end{array}$ \\
\hline 6) & Formação e sustentabilidade & $\begin{array}{l}\text { O município de São Francisco do Sul possui apenas uma Universidade a qual oferece apenas três } \\
\text { cursos: Administração, Ciências Biológicas e Biologia Marinha. }\end{array}$ \\
\hline 7) & Recursos & Não existe recurso ou fundos exclusivos para o gerenciamento costeiro no município. \\
\hline 8) & Conhecimento e informação & $\begin{array}{l}\text { Um projeto realizado pela UNIVILLE elaborou todo o diagnóstico com base nos volumes publica- } \\
\text { dos dando condição à prefeitura de conhecer a atual situação de sua orla marítima. }\end{array}$ \\
\hline 9) & Educação e sustentabilidade & $\begin{array}{l}\text { A secretaria de meio ambiente é a única secretaria responsável pelos projetos de educação e cons- } \\
\text { cientização ambiental e urbanística junto a escolas e a comunidade de São Francisco do Sul. }\end{array}$ \\
\hline 10) & Participação & $\begin{array}{l}\text { A população é convocada para audiências públicas e comparece em pequeno número e as associa- } \\
\text { ções de moradores tem sua participação diretamente associada a interesses locais e próprios. }\end{array}$ \\
\hline
\end{tabular}

Fonte: Adaptado de Barragán Muñoz (2010).

\section{Considerações}

A análise do decálogo permitiu conhecer e esclarecer a atual situação do município em relação ao seu ordenamento territorial, sobretudo no que diz respeito ao entendimento da prefeitura sobre a 
zona costeira e sua gestão. Cada item analisado permitiu a criação de um panorama com as principais deficiências do município, bem como a identificação das ações realizadas e ações prioritárias para a gestão pública, como iniciar o projeto orla no município.

Devido a não existência de uma política pública exclusiva para o gerenciamento costeiro em São Francisco do Sul, concluiu-se que se faz como prioridade a criação do Plano Municipal de Gerenciamento Costeiro, em conjunto com a capacitação dos gestores. Isto se justifica por conta do não entendimento acerca do conceito de zona costeira por parte dos gestores, mesmo que, de acordo com o PNGC, todo o município de São Francisco do Sul seja parte do bioma costeiro do Brasil.

O gerenciamento costeiro no município é incipiente e, mesmo com a interação entre as três secretarias mencionadas, a secretaria de meio ambiente detém a maior parte das informações, como as bases cartográficas georreferenciadas e o maior número de profissionais capacitados e habilitados a participar de ações que envolvem o gerenciamento costeiro.

Cabe ao órgão público interpretar o uso e ocupação de seu território, bem como seguir as diretrizes do PNGC e seus respectivos instrumentos. Atualmente, a faixa litorânea, ou orla marítima, não é a principal preocupação da prefeitura, tendo em vista que apenas $30 \%$ da orla marítima estão ocupados (LIMA, VIEIRA; SCHERER, 2017) e os principais problemas estão relacionados às áreas interioranas do município. Ainda assim a elaboração do Projeto Orla é uma das principais ações a serem tomadas pela prefeitura.

Todos os itens do decálogo devem ser observados sendo que, conforme constatado, para que o gerenciamento costeiro do município de São Francisco do Sul tenha continuidade, é necessária a criação de uma comissão que tenha como objetivo a publicação de um Plano Municipal de Gerenciamento Costeiro.

O presente trabalho foi realizado com apoio da Coordenação de Aperfeiçoamento de Pessoal de Nível Superior - Brasil (CAPES) - Código de Financiamento 001. Os autores agradecem também ao Laboratório de Gestão Costeira Integrada (LAGECI), do Programa de Pós-Graduação em Geografia da Universidade Federal de Santa Catarina e a Prefeitura Municipal de São Francisco do Sul. 
Referências

ANDRADE, J; SCHERER, M. E. G. Decálogo da gestão costeira para Santa Catarina: avaliando a estrutura estadual para o desenvolvimento do Programa Estadual de Gerenciamento Costeiro. Desenvolvimento e Meio Ambiente, v. 29, 139-154, 2014.

ANTAQ. Agência nacional de Transportes Aquaviários. Desempenho do setor aquaviário 2017. Oportunidades e melhorias portuárias. Disponível em: <http://antaq.gov.br/Portal/PDF/Anuarios/ApresentacaoAnuario2017.pdf> Acesso: 19 fev 2018. Brasília, 2018.

ASMUS, M. L; KITZMANN, D; LAYDNER, C; TAGLIANI, C. R. Gestão Costeira no Brasil: instrumentos, fragilidades e potencialidades. Gestão Costeira Integrada, v. 1, n. 5, p.52-57, 2006.

BABITONGA ATIVA. (2017) Diagnóstico sócio ambiental do Ecossistema Babitonga. Joinville, 2 ed.

BARRAGÁN MUÑOZ, J. Las áreas litorales de España: del análisis geográfico a la gestión integrada. Ariel, 2004.

BARRAGÁN MUÑOZ, J.; RUIZ, A. J. C.; CAYERO, M. L. P. Estrategia andaluza de gestión integrada de zonas costeras. Junta de Andalucía: Consejería de Medio Ambiente, 2008.

BARRAGÁN MUÑOZ, J.M. (Org.). Manejo Costero Integrado y Política Pública en Iberoamérica: Un diagnóstico. Necesidad de Cambio. Cádiz: Red IBERMAR (CYTED), 2010.

Manejo Costero Integrado y Política Pública en Iberoamérica: Propuestas para la acción. Cádiz: Red IBERMAR (CYTED), 2011.

Manejo Costero Integrado en Iberoamérica: Diagnóstico y propuestas para una nueva política pública. Cádiz: Red IBERMAR (CYTED), 2012

BRASIL. Decreto $n^{\circ} 9.760$ de 5 de setembro de 1946. Dispõe sobre os bens imóveis da União dá outras providências. Brasília: DOU de 6/9/1946

. Lei $n^{\circ} 6.938$ de 31 de agosto de 1981. Dispõe sobre a Política Nacional do Meio Ambiente, seus fins e mecanismos de formulação e aplicação, e dá outras providências. Brasília:

DOU de 2/9/1981.

. Lei $\mathbf{n}^{\circ} \mathbf{7 . 6 6 1}$ de 16 de maio de 1988. Institui o Plano Nacional de Gerenciamento Costeiro e dá outras providências. Brasília: DOU de 18/5/1998.

. Lei $n^{\circ} 9.636$ de 15 de maio de 1998. Dispõe sobre a regularização, administração, aforamento e alienação de bens imóveis de domínio da União. Brasília: DOU de 18/5/1998

Decreto n. 5.300 de 7 de dezembro de 2004. Regulamenta a Lei n. 7.661, de 16 de maio de 1988, que institui o Plano Nacional de Gerenciamento Costeiro - PNGC. Brasília: DOU de 8/12/2004.

Decreto $n^{\circ} 5.377$ de 23 de fevereiro de 2005. Aprova a Política Nacional para os Recursos do Mar - PNRM. Brasília: DOU de 24/4/2005. 
BRASIL. Lei $\mathbf{n}^{\circ} \mathbf{1 1 . 4 2 8}$ de 22 de dezembro de 2006. Dispõe sobre a utilização e proteção da vegetação nativa do Bioma Mata Atlântica. Brasília: DOU de 9/1/2007.

Lei Federal $n^{\circ} 12.651$ de 25 de maio de 2012. Dispõe sobre a proteção da vegetação nativa. Brasília: DOU de 28/52012.

. Lei Federal $n^{\circ} 13.240$ de 30 de dezembro de 2015. Dispõe sobre a administração, a alienação a transferência de gestão de imóveis da União e seu uso para a constituição de fundos. Brasília, DOU de 2/6/2016.

CIRM. Resolução $n^{\circ}$ 5, de 3 de dezembro de 1997. Aprova o Plano Nacional de Gerenciamento Costeiro II Brasil, 1997.

CREMER, M. J.; MORALES, P. R. D.; OLIVEIRA, T M. N. Diagnóstico Ambiental da Baía da Babitonga. Joinville: Editora Univille, 2006. 256 p.

DIEDERICHSEN, S. D. et al. Gestão costeira no município de Florianópolis, SC, Brasil: Um diagnóstico. Revista de Gestão Costeira Integrada, v. 13, n. 4, p. 499-512, 2013.

FREIRE, O. D. da S. Projeto Orla: Fundamentos para gestão integrada. Brasília: MMA/SQA; Brasília: MP/SPU, 2002.

GUIÃO, V. Gestão da Orla Marítima em Bombinhas: priorização dos planos de ação propostos pelo Projeto Orla para a praia de Bombas. TCC (Graduação em Geografia) - Universidade Federal de Santa Catarina (UFSC), 2015.

IBGE - Instituto Brasileiro de Geografia e Estatística. Censo Demográfico. Brasília: 2010. Disponível em: <http://www.ibge.gov.br>.

. Instituto Brasileiro de Geografia e Estatística. Áreas Especiais Cadastro de Municípios da Zona Costeira. Disponível em:<http://www.ibge.gov.br/home/geociencias/geogra fia/costeira.shtm?c=5> 2010 .

LAVILLE, C. e DIONNE, J. A construção do saber: manual de metodologia da pesquisa em ciências humanas. Porto Alegre: Artmed, 1999.

LIMA, A. de S. de; VIEIRA, C. V.; SCHERER, M. E. G. Gestão costeira integrada de São Francisco do Sul, SC: subsídios para a implantação do Projeto Orla. In: Melo Júnior, J. C. F. de; Oliveira, T. M. N. de (Orgs.). Ciências ambientais: ensaios e perspectivas. Joinville: Editora Univille, 2017.

LIMA, A. de S. de; SCHERER, M. E. G. Interação de fatores físicos e humanos na ocupação de zonas costeiras: o caso de São Francisco do Sul, SC. In: Pereira, S.D et al. (Eds.) O Homem e o Litoral: Transformações na paisagem ao longo do tempo. Editora FAPERJ, p. 168-183, 2017.

ONETTI, J. Garcia; SANABRIA, J. GARCIA; BARRAGAN MUÑOZ, J.M. Las Comunidades Autonomas y la gestion integrada de las areas litorales de Espana. Materiales para un debate sobre gobernanza. REGIAL - Proyecto Red Espanola de Gestion Integrada de Areas Litorales, Cadiz, 2011. 220p. ISBN: 978-8469514023.

SANTA CATARINA. Decreto n' $\mathbf{5 . 0 1 0}$ de 22 dezembro de 2006. Institui o Plano Estadual de Gerenciamento Costeiro de Santa Catarina. Brasil, 2006. 
SANTA CATARINA. Lei $\mathbf{n}^{\circ}$ 14.675, de 13 de abril de 2009. Institui o Código Estadual do Meio Ambiente e estabelece outras providências. Brasil, 2009.

. Secretaria de Estado do Planejamento. Governo de Santa Catarina (Org.). Implantação do Plano Estadual de Gerenciamento Costeiro: Diagnóstico Sócio Ambiental Setor 1 Norte. Florianópolis: SPG, 2010. 470 p.

SÃO FRANCISCO DO SUL. Prefeitura Municipal de São Francisco: Administração. 2017. Disponível em: <http://www.saofranciscodosul.sc.gov.br/>. Acesso em: 23 jan. 2018.

. Lei $n^{\circ} 603$ de 26 de março de 1976. Dispõe sobre as construções e edificações no município de São Francisco do Sul e dá outras providências. Brasil, 1976.

. Decreto $\mathrm{n}^{\circ} \mathbf{2 . 6 6 4}$ de 8 de agosto de 2017. Institui o processo participativo de revisão do plano diretor do município de São Francisco do Sul e seu regimento. Brasil, 2017.

. Lei $\mathbf{n}^{\circ} 763$ de 22 de abril de 1981 . Dispõe sobre o zoneamento do município de São Francisco do Sul Brasil, 1981.

. Lei n $^{\circ} 17$ de 13 de dezembro de 2006. Institui o Plano Diretor de São Francisco do Sul. Brasil, 2006.

. Lei Complementar $n^{\circ} 43$ de 5 de setembro de 2013. Altera a redação da Lei $n^{0} 17$ de 13 de dezembro de 2006, que institui o Plano Diretor Municipal de São Francisco do Sul e dá outras providências. Brasil, 2013.

. Lei Complementar $n^{\circ} 44$ de 5 de setembro de 2013. Altera a redação da Lei $n^{\circ} 763$ de 22 de abril de 1981 que dispõe sobre o zoneamento de São Francisco do Sul. Brasil, 2013.

SCHERER, M; EMERIM, E., FELIX, A.; PRATA, P. Gerenciamento costeiro municipal: uma abordagem metodológica. Município de Anchieta, ES. Editora Nova Letra, 2013. 192 p. ISBN 9788576828259. 